\title{
Etnomatematika: Tinjauan Aspek Geometris Batik Lebak Provinsi Banten
}

\author{
Andri Imam Subekhi ${ }^{*}$, Hepsi Nindiasari ${ }^{2}$, Sukirwan $^{3}$ \\ 1,2,3Program Pascasarjana Pendidikan Matematika, Universitas Sultan Ageng Tirtayasa, \\ Serang, Indonesia; andriimamsubekhi@gmail.com ${ }^{1 *}$; hepsinindiasari@untirta.ac.id $^{2}$; \\ sukirwan@untirta.ac.id ${ }^{3}$
}

Info Artikel: Dikirim: 3 Juni 2020 ; Direvisi: 2 Juli 2020; Diterima: 25 Februari 2021

Cara sitasi: Subekhi, A. I., Nindiasari, H., \& Sukirwan. (2021). Etnomatematika: Tinjauan Aspek Geometris Batik Lebak Provinsi Banten. JNPM (Jurnal Nasional Pendidikan Matematika) $5(1), 81-93$.

\begin{abstract}
Abstrak. Etnomatematika merupakan matematika yang terdapat dalam budaya. Tujuan dari penelitian ini untuk meninjau aspek-aspek geometris matematika pada Batik Lebak Banten. Metode penelitian yang digunakan adalah metode kualitatif dengan pendekatan etnografi. Adapun teknik pengumpulan data yang digunakan yaitu studi pustaka, wawancara dan dokumentasi. Teknik analisis data yang digunakan yaitu reduksi data, penyajian data, dan penarikan kesimpulan. Pengecekan keabsahan data dilakukan dengan perpanjangan pengamatan, meningkatkan ketekunan, menggunakan bahan referensi. Hasil dari penelitian ini adalah pada Batik Lebak Banten terdapat aspek geometris matematika berupa bangun datar, dan teori graf. Adapun bangun datar yang terdapat pada batik ini yaitu belah ketupat, persegi panjang, lingkaran, dan segitiga. Sedangkan teori graf yang terdapat pada batik ini yaitu graf star.
\end{abstract}

Kata Kunci: Etnomatematika, Batik Lebak Banten, Aspek Geometris Matematika.

\begin{abstract}
Ethnomatematics is mathematics found in culture. The purpose of this study is to review the geometrical aspects of mathematics on Lebak Banten Batik. The research method used was a qualitative method with an ethnographic approach. The data collection techniques used were literature study, interviews and documentation. Data analysis techniques used were data reduction, data presentation, and conclusions. Checking the validity of the data is done by lengthening observations, increasing perseverance, using reference material. The results of this study were in Lebak Banten there are geometrical aspects of mathematics in the form of flat shapes, and graph theory. The flat shape found in this batik is rhombus, rectangle, circle and triangle. While the graph theory contained in this batik is star graph.
\end{abstract}

Keywords: Ethnomatematics, Batik Lebak Banten, Geometric Aspects Of Mathematics.

\section{Pendahuluan}

Menurut Ridwan (2018), pada masa sebelum sekolah dan di luar sekolah di dunia ini hampir semua anak telah menjadi "matherate" artinya, mereka mampu mengembangkan kemampuan untuk menghitung, menggunakan bilangan, dan menggunakan beberapa pola inferensi. Tetapi, seorang individu yang dengan sempurna telah mampu menggunakan bilangan, bentuk geometris, operasi, dan gagasan, ketika di sekolah dihadapkan pada pendekatan yang sama sekali baru dan formal mengenai fakta-fakta. Sebagai 
akibatnya, terbentuklah penyumbatan psikologis yang tumbuh sebagai penghalang antara perbedaan model-model numerik yang dipelajari di sekolah dengan pemikiran geometris yang sudah dipelajarinya dari kehidupan nyata sebelum atau di luar sekolah, sehingga tahap awal pendidikan matematika memberikan pengaruh pada anak rasa kegagalan, ketergantungan, bahkan kehilangan kemampuan matematis yang telah dimiliki pada masa pra sekolah. Hal tersebut menunjukkan bahwa pembelajaran matematika di sekolah terlepas dari kehidupan nyata yang kaya akan budaya dan peradaban.

Berbagai daerah tentunya memiliki cerita yang berbeda-beda. Hal ini menandakan bahwa Indonesia adalah negara yang memiliki kekayaan budaya luar biasa yang bisa menjadi aset bangsa (Setiawan \& Listiana, 2021). Indonesia menetapkan bahwa pada tanggal 2 Oktober adalah hari Batik Nasional sebagai wujud kebanggaan bangsa Indonesia terhadap batik yang telah mendapatkan pengakuan dunia dan menjadi warisan budaya yang patut dikembangkan (Arwanto, 2017).

Etnomatematika merupakan sebuah pendekatan pembelajaran yang dapat diterapkan di kelas. Kondisi Indonesia yang memiliki beragam budaya menjadi pendukung utama pendekatan etnomatematika untuk diterapkan (Choirudin, Ningsih, Anwar, Sari, dan Amalia, 2020). Matematika menjadi mata pelajaran yang wajib yang diberikan di setiap jenjang pendidikan mulai dari pendidikan dasar, menengah sampai dnegan perguruan tinggi. Tujuan mata pelajaran matematika diberikan salah satunya membekali siswa agar dapat berpikir logis, sistematis serta berpikir kreatif dan berpikir kritis (Nurjamil dan Nurhayati, 2019). Masyarakat Indonesia dengan kehidupan yang beragam tidak menutup kemungkinan akan dipengaruhi oleh budaya sekitar sebagai warisan yang dibawakan sejak lampau. Selain itu, budaya asing yang bebas masuk ke Indonesia melalui penyebaran agama sehingga menyebabkan terjadinya proses akulturasi yang mengakibatkan bertambahnya keberagaman budaya yang sebelumnya telah ada. (Afriyanty, dan Izzati, 2019).

Tuntutan kurikulum dan target kompetensi dasar yang harus dipenuhi oleh guru pada saat ini yang menyebabkan pembelajaran matematika menjadi kurang bermakna, hal ini terlihat bahwa pemahaman konsep matematika masih sangat kurang dan siswa seringkali tidak mengenal budaya setempat yang sekiranya dapat diaplikasikan dalam pembelajaran matematika (Nisa, 2020). Keberagaman yang bermacam itu sangat dikenal oleh negara lain. Karena budayanya, banyak negara asing yang tertarik untuk mendatangi 
Indonesia, bahkan budaya asing bebas masuk melalui penyebaran agama (Sahilda \& Izzati, 2020).

Keberadaan inovasi pembelajaran sangat diperlukan sehingga pembelajaran matematika dapat menjadi lebih menyenangkan. Hal-hal yang nyata dan berhubungan dengan pengalaman peserta didik sehari-hari dapat dijadikan sebagai sumber belajar yang menarik (Lubis dan Widada, 2020). Ilmu Pengetahuan dan Teknologi (IPTEK) semakin berkembang seiring dengan perkembangan zaman. Hal ini memberikan kontribusi yang cukup besar dalam mengembangkan teknologi pendidikan. Inovasi dalam bidang pendidikan pun semakin berkembang pesat. Di tengah perkembangan teknologi pendidikan, kurikulum pendidikan pun menuntut keterlibatan budaya dalam pembelajaran di sekolah dengan tujuan agar peserta didik dapat menjadi generasi yang berkarakter dan mampu menjaga serta melestarikan budaya sebagai landasan karakter bangsa (Fajriyah, 2018).

Budaya merupakan cara hidup atau kebiasaan-kebiasaan yang berkembang dalam sekelompok orang yang diwariskan secara turun temurun. Setiap kelompok memiliki keunikan tersendiri dalam menjalankan aktivitas kehidupannya, mulai dari bahasa, pakaian, makanan, bangunan, dankesenian (Susanty, Zaenuri dan Kharisudin, 2019). Namun, pembelajaran matematika menemui kendala dalam pelaksanaanya. Kendala tersebut muncul karena terdapat ketidaksesuaian yang siswa temukan di luar sekolah (Firdaus, Widodo, Taufiq, dan Irfan, 2020).

Matematika dianggap sebagai sesuatu yang netral dan terbebas dari budaya (culturraly-free). Seperti yang diungkapkan oleh Prabawati (2016), bahwa "mathematics always taught in scholl as a culturaly free subject that involved learning supposedly universally accepted facts, concept and content". Matematika dipelajari di sekolah sebagai mata pelajaran yang tidak terkait dengan budaya yang secara umum pembelajarannya meliputi fakta-fakta, konsep, dan materi. Matematika juga dianggap sebagai ilmu pengetahuan yang sempurna dengan kebenaran yang objektif dan dirasakan jauh dari realitas kehidupan seharihari. Hal ini sejalan dengan aktivitas perdagangan atau jual beli barang yang dilakukan oleh manusia memerlukan matematika untuk menghitung besar keuntungan atau kerugian yang dialami.

Menurut Prabawati (2016), dari hasil pertemuan International Community of Mathematics Education menyebutkan bahwa permasalahan yang terkait dengan budaya mau tidak mau akan mengelilingi proses pembelajaran matematika, bahkan semua bentuk-bentuk matematika. Hal ini 
berkesinambungan dengan pembelajaran matematika sekolah saat ini, banyak mengadopsi dari pembelajaran matematika negara luar yang dianggap lebih maju. Indonesia dengan keragaman budayanya sudah seharusnya memasukkan nilai-nilai budaya setempat ke dalam pembelajaran matematika, agar matematika tidak dianggap sebagai ilmu pengetahuan yang jauh dari realitas kehidupan.

Matematika merupakan suatu kegiatan sosial dan aktivitas manusia (Gravemeijer, 1997). Matematika berupaya memahami pola yang terjalin, baik dalam lingkungan sekitar yang merupakan dunia nyata, maupun dalam alam pikiran kita. Meskipun bahasa matematika berlandaskan pada suatu aksiomaaksioma yang ketat, akan tetapi karena matematika juga merupakan aktivitas sosial. Transformasi ini menuntut adanya perubahan pada muatan kurikulum dan strategi pembelajaran yang berfokus pada upaya; menemukan penyelesaian, bukan hanya menghafal prosedur; menjelajahi pola, tidak hanya menghafal rumus, dan merumuskan tebakan, tidak hanya mengerjakan latihan. Sejalan dengan pendapat tersebut, bahwa hakekat pendidikan matematika mempunyai dua arah pengembangan, yaitu pengembangan untuk kebutuhan masa kini dan masa akan datang. Sejalan pendapat tersebut siswa yang paham akan suatu konsep matematis umumya akan memiliki pola pikir yang jauh lebih baik ketimbang siswa yang tidak paham suatu konsep, demikian pula siswa yang memiliki proses berpikir matematika yang baik, maka konsep yang dimilikipun juga diasumsikan baik.

Hal ini juga berlaku umum bagi suatu individu maupun kelompok sosial bahwa kekurangpahaman akan suatu konsep menyebabkan proses berpikirnya juga menyesuaikan dengan apa yang dipahaminya. Oleh karena itu, lingkungan merupakan salah satu faktor utama dalam membentuk suatu pola dan pemahaman akan suatu hal.

Etnomatematika merupakan salah satu kajian yang baru. Sebagai salah satu kajian yang baru, etnomatematika berperan penting dalam mengeksplorasi nilai-nilai luhur pada kebudayaan masyarakat. Sependapat dengan D'Ambrosio mengungkapkan etnomatematika merupakan matematika yang dipraktikkan oleh kelompok budaya seperti masyarakat adat, kelompok buruh, masyarakat perkotaan dan pedesaan, anak-anak dari kelompok usia tertentu, dan lainnya (Maharani, 2018). Hal tersebut menunjukan bahwa pembelajaran matematika di sekolah terlepas dari kehidupan nyata yang kaya akan budaya dan peradaban. 
Oleh karena itu etnomatematika merupakan matematika yang tumbuh dan berkembang dalam kebudayaan tertentu. Sedangkan budaya merupakan suatu kebiasaan yang mengandung unsur-unsur nilai penting dan fundamental yang diwariskan dari generasi ke generasi. Dalam etnomatematika kebiasaan-kebiasaan yang dilakukan tidak lepas dari penerapan konsep matematika, sehingga memberikan hasil unik dan beragam (Maharani, 2018). Secara singkat, pengertian dari etnomatematika adalah bentuk matematika yang dipengaruhi oleh budaya.

\section{Metode}

Jenis penelitian ini merupakan penelitian kualitatif dengan pendekatan etnografi. Metode yang digunakan dalam penelitian ini adalah eksplorasi dengan pendekatan etnografi. Eksploratif Metode adalah metode yang digunakan untuk menemukan, mengeksplorasi dan menemukan gejala atau kejadian dengan melakukan penilaian gejalanya. Sedangkan pendekatan etnografi, adalah penelitian pendekatan dengan keterlibatan peneliti dalam asosiasi sunda di antara lokasi yang dipilih. Oleh karena itu sejalan dengan penelitian sebelumnya, pendekatan etnografi digunakan untuk mendapatkan deskripsi tentang budaya yang terdapat pada Batik Lebak Banten. Sedangkan kualitatif digunakan untuk mendeskripsikan dan menganalisis informasi secara keseluruhan.

Penelitian ini dilakukan mulai November 2019 hingga April 2020. Penelitian ini dilakukan di Kampung Pancur, Desa Bojong leles, Kecamatan Cibadak, Kabupaten Lebak, Banten. Lokasi ini dipilih dikarenakan Desa bojong leles merupakan tempat terciptanya Batik Lebak Banten. Informan dalam penelitian ini yaitu seorang pembatik di Desa bojong leles, Lebak Banten dan seorang pemilik Batik Lebak gerai chanting pradana. Dimana penyajian data pada penelitian kualitatif berbentuk deskriptif atau kata-kata. Teknik pengumpulan data yang dilakukan pada penelitian ini yaitu studi pustaka, wawancara dan dokumentasi. Instrumen utama dalam penelitian ini yaitu peneliti sendiri. Teknik analisis data yang digunakan dalam penelitian ini yaitu reduksi data, penyajian data, kesimpulan. Pengecekan keabsahan data yang dilakukan pada penelitian ini yaitu perpanjangan pengamatan, meningkatkan ketekunan, menggunakan bahan referensi.

\section{Hasil dan Pembahasan}

Batik Lebak sudah memiliki hak paten. Namun yang lebih penting adalah bagaimana ke depannya batik yang telah mendapatkan hak patennya dari kementerian hukum tersebut bisa berkembang di Lebak dan menjadi kekuatan ekonomi baru warga Lebak. Ada dua belas motif Batik Lebak yang 
telah mendapatkan hak paten dan mulai dipasarkan yaitu batik motif gula sakojor, batik motif pare sapocong, batik motif kahirupan baduy, batik motif caruluk saruntuy, batik motif Lebak bertauhid, batik motif angklung buhun, batik motif kalimaya, batik motif sadulur, batik motif seren taun, batik motif sawarna, batik leuit sijimat, dan batik motif rangkasbitung.

Pada bagian ini menjelaskan topik matematika apa saja yang terdapat di motif Batik Lebak. Motif Batik Lebak memiliki banyak sekali jenis motifnya, seingga terdapat beberapa konsep geometri yang terkandung di motif Batik Lebak, sebagai berikut.

\section{a. Belah Ketupat}

Belah ketupat adalah segiempat yang memiliki dua pasang sisi yan sejajar yang semua panjang sisinya semua sama. Pada motif batik gula sakojor yang memiliki geometri belah ketupat. Seperti pada gambar 1.

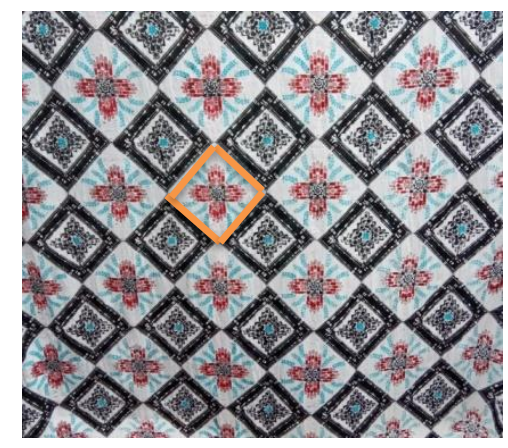

Gambar 1. Motif Gula Sakojor (Dokumentasi pribadi)

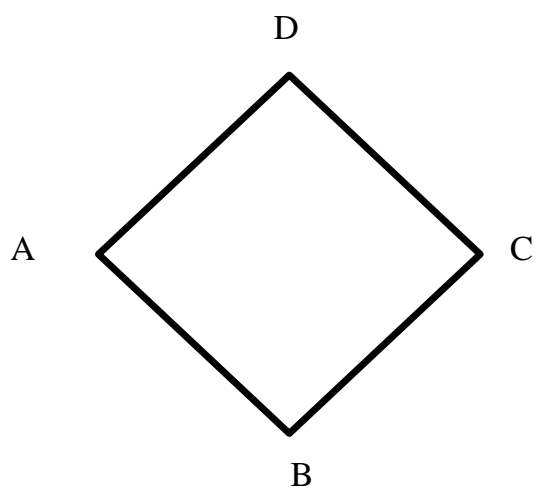

Gambar 2. Belah Ketupat

Berdasarkan Gambar 1 diketahui bahwa motif gula sakojor memiliki bentuk belah ketupat seperti pada belah ketupat ABCD. 
Motif batik dengan bentuk geometri belah ketupat juga terdapat pada motif batik Madura (Zayyadi, 2017), dimana pada batik tersebut terdapat pola geometri yang dapat digunakan untuk mengkontruksi pemikiran atau pemahaman siswa sebagai peserta didik. Konsep-konsep matematika (etnomatematika) pada motif Batik Madura tersebut dapat digunakan dalam proses pembelajaran utamanya untuk memperkenalkan budaya/ciri khas lokal khususnya Madura pada siswa sehingga akan terbangun pengetahuan yang erat dalam pemikiran siswa karena konsep itu muncul dari budaya mereka sendiri. Dengan demikian pembelajaran matematika di kelas akan lebih bermakna karena hal ini sudah tidak asing lagi bagi siswa. Konsepkonsep matematika yang abstrak akan menjadi konkret apabila siswa sudah mengetahui konsep matematika pada motif batik lokal tersebut.

b. Persegi panjang

Persegi panjang adalah segiempat yang memiliki dua pasang sisi sejajar dan memiliki sudut siku-siku. Pada motif Batik Lebak banyak sekali yang memiliki geometri dengan bentuk persegi panjang yaitu adalah motif pare sapocong seperti pada Gambar 3.

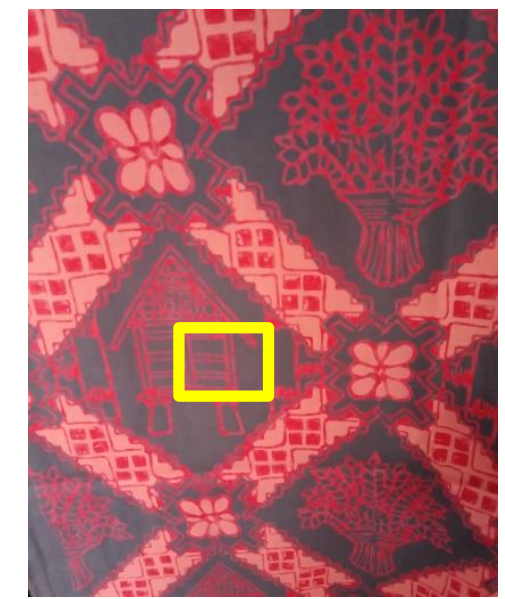

Gambar 3. Motif Pare Sapocong

(Dokumentasi pribadi)

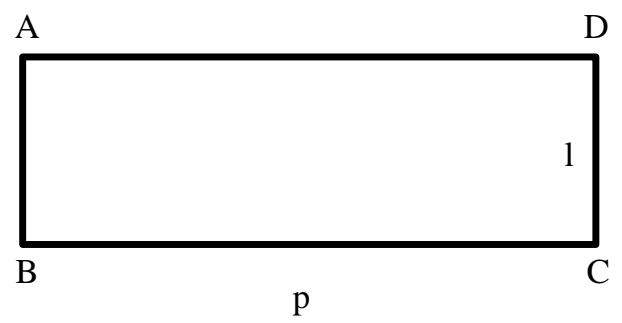

Gambar 4. Persegi Panjang 
Motif batik pare sapocong memiliki persegi panjang pada motifnya ini memiliki makna yang luar biasa. Pare sapocong dalam ikatan padi yang dikumpulkan dari enam genggam padi diikat menjadi satu. Tradisi ini masih dipertahankan di kasepuhan Lebak Selatan, dengan tujuan untuk mempermudah pengeringan, pengangkutan dan penyimpanan. Bibit padi yang digunakan jenis padi besar seperti padi cere, gantang, kui, seksek, sirikuning, dan ketan yang memiliki umur panen enam bulan. Adapun alat panen yang digunakan dengan entem (ani-ani) untuk memotong tangkai padinya. Motif batik ini mempunyai filosofi melambangkan sumber kemakmuran hidup dengan ikatan persaudaraan dan kerendahan hati. Dan motif batik sadulur dilambangkan oleh dua jenis leuit (lumbung padi) yang berada dikesepuhan Lebak Selatan dan jenis leuit suku Baduy.

Dari dua jenis leuit yang berbeda tapi mempunyai fungsi dan manfaat sama yaitu sebagai tempat penyimpanan padi. Ornamen batik sadulur terdiri dari dua buah leuit (lumbung padi), leuit kesepuhan Lebak selatan, dan leuit suku baduy dengan ornamen tambahan motif tenun baduy dan angklung. Motif batik ini mempunyai filosofi melambangkan kekeluargaan, kesejahteraan dan kebersamaan. dan Bertauhid merupakan moto kabupaten Lebak yang berarti bersih, taqwa, hijau dan damai.

Ornamen utama batik ini terdiri dari surau dan bedug. Surau dan bedug masih tetap dipertahankan dan masih dapat ditemui di lingkungan masyarakat, sebagai sarana siar islam, kegiatan sosial (musyawaroh), dan pendidikan agama. Sedangkan bedug digunakan sebagai pengingat kita sebagai umat islam juga sebagai media sosial. Motif batik ini mempunyai filosofi melambangkan citra kehidupan yang religious dengan penuh keimanan dan ketaqwaan kepada Allah SWT.

Berdasarkan Gambar 3 terlihat jelas bahwa motif pare sapocong dan motif Lebak bertauhid pada motif Batik Lebak tersebut memiliki motif geometri persegi panjang. Motif batik dengan bentuk geometri persegi panjang juga terdapat pada batik Indramayu dengan motif batik parang teja, sawat dan serujit. Dalam motif Serujit ini terdapat unsur matematik diantaranya bentuk yang dimaksud kotak-kotak jaring membentuk persegi, motif sampingnya membentuk segitiga dan segitiga terdapat bentuk persegi panjang (Sudirman, Son dan Rosyadi, 2018).

c. Lingkaran

Lingkaran adalah himpunan semua titik di bidang datar yang berjarak sama dari suatu titik tetap di bidang tersebut. Titik tetap lingkaran itu dinamakan 
pusat lingkaran, sedangkan jarak dari suatu titik pada lingkaran ke titik pusat dinamakan jari-jari lingkaran Pada motif Batik Lebak banyak sekali yang memiliki geometri dengan bentuk lingkaran yaitu adalah motif caruluk saruntuy, motif kalimaya, motif Lebak bertauhid dan motif rangkasbitung seperti pada gambar 5 .

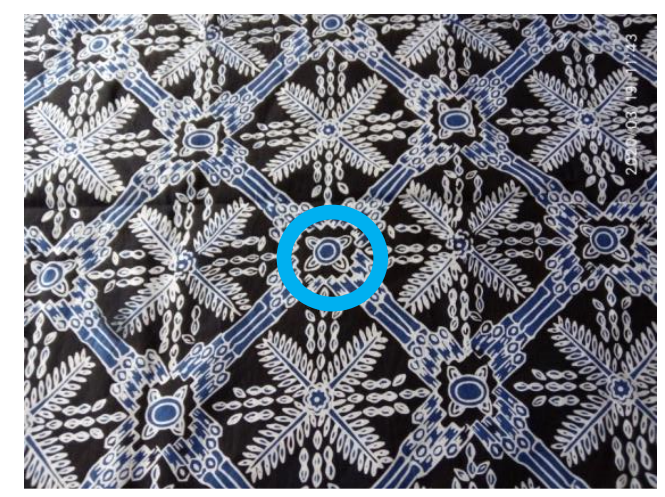

Gambar 5. Motif Caruluk Saruntuy (Dokumentasi pribadi)

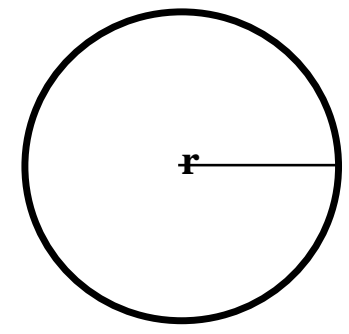

Gambar 6. Lingkaran

Berdasarkan Gambar 5 terlihat jelas bahwa motif caruluk saruntuy, motif kalimaya, motif Lebak bertauhid dan motif rangkasbiutng pada motif batik Lebak tersebut memiliki motif geometri lingkaran. Bentuk bangun datar lingkaran juga terdapat pada motif batik dari daerah Jawa yaitu batik Jlamprang. Pada batik ini terdapat lingkaran-lingkaran kecil di bagian dalam dan di bagian luar membentuk pola persegi karena lingkaran kecil diletakkan sejajar.

d. Segitiga pada motif kahirupan baduy dan motif sadulur

Segitiga adalah tiga ruas yang berbeda di mana titik ujung suatu ruas garis berimpit dengan titik pangkal titik pangkal ruas garis lain. Pada motif kahirupan baduy dan motif sadulur terdapat titik-titik yang membentuk segitiga, seperti pada gambar 7 . 


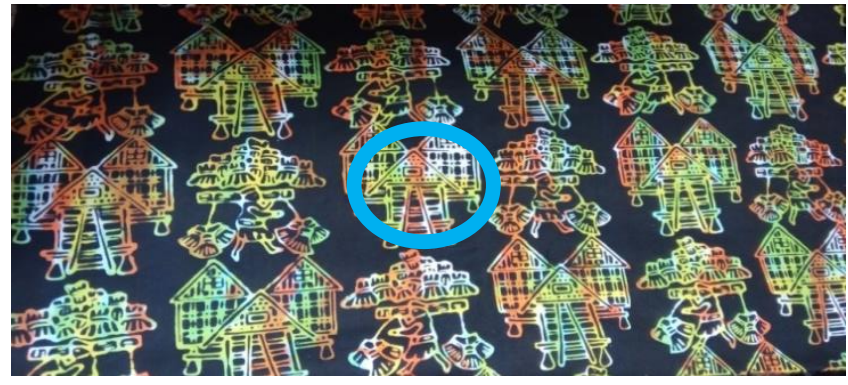

Gambar 7. Motif Kahirupan Baduy (Dokumentasi pribadi)

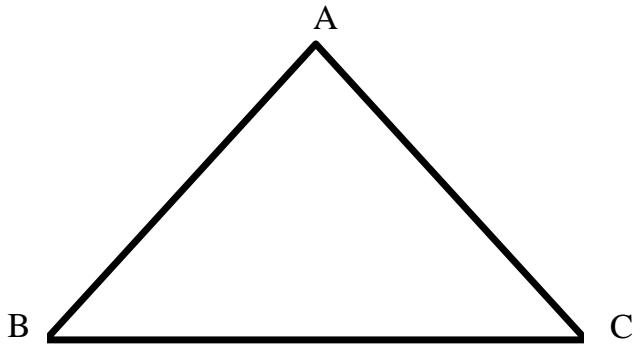

Gambar 8. Segitiga

Kahirupan baduy adalah aktivitas keseharian masyarakat suku baduy. Ornamen utama batik ini terdiri dari rumah panggung sebagai tempat tinggal suku baduy, dengan mata pencaharian utamanya berladang (huma) yang dilambangkan dengan adanya ornament lantaian (tempat jemuran padi), dan leuit (tempat penyimpanan padi) serta aktivitasnya. Motif batik ini mempunyai filosofi melambangkan kehidupan bersahaja dengan kelestarian alam yang kental dengan budaya, selanjutnya motif batik sadulur dilambangkan oleh dua jenis leuit (lumbung padi) yang berada dikesepuhan Lebak selatan dan jenis leuit suku baduy. Dari dua jenis leuit yang berbeda tapi mempunyai fungsi dan manfaat sama yaitu sebagai tempat penyimpanan padi. Ornamen batik sadulur terdiri dari dua buah leuit (lumbung padi), leuit kesepuhan Lebak selatan, dan leuit suku baduy dengan ornamen tambahan motif tenun baduy dan angklung. Motif batik ini mempunyai filosofi melambangkan kekeluargaan, kesejahteraan dan kebersamaan.

Dalam motif Serujit pada Batik Indramayu terdapat unsur matematik diantaranya bentuk yang dimaksud kotak-kotak jaring membentuk persegi, motif sampingnya membentuk segitiga (Sudirman, Son \& Rosyadi, 2018). Pola segitiga terdapat juga pada budaya lain yaitu budaya Jawa. Pada budaya Jawa terdapat rumah Joglo dimana pada bagian atapnya terdapat pola segitiga yang khas (Pramudita \& Rosnawati, 2019). 
Motif sedulur pada gambar 9 memuat Graf Star dari motif Batik Lebak terdapat di motif sadulur.

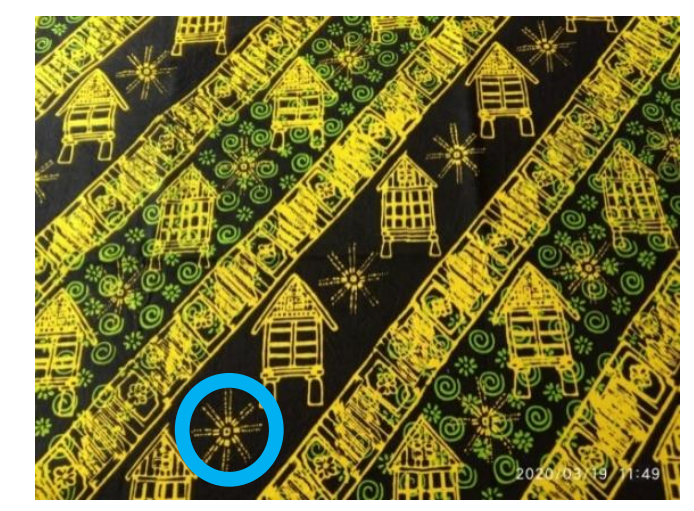

Gambar 9. Motif Sadulur (Dokumentasi pribadi)

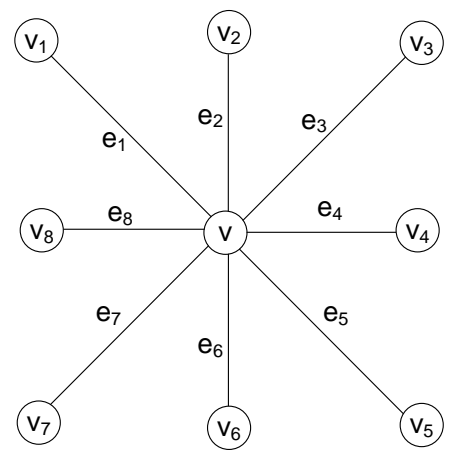

Gambar 10. Graf Star $K_{1,8}$

Graf pada Gambar10merupakan grafdengan himpunan titik $V(G)=$ $\left\{v_{1}, v_{2}, v_{3}, v_{4}, v_{5}, v_{6}, v_{7}, v_{8}\right\}$ dan himpunan sisi $E(G)=\left\{e_{1}, e_{2}, e_{3}, e_{4}, e_{5}, e_{6}, e_{7}, e_{8}\right\}$ dimana $e_{1}=\left(v, v_{1}\right), e_{2}=\left(v, v_{2}\right), e_{3}=\left(v, v_{3}\right), e_{4}=\left(v, v_{4}\right), e_{5}=\left(v, v_{5}\right), e_{6}=$ $\left(v, v_{6}\right), e_{7}=\left(v, v_{7}\right), e_{8}=\left(v, v_{8}\right)$.

Pola graf star juga terdapat pada batik motif Ceplok dari daerah Jawa (Pramudita \& Rosnawati, 2019). Selain itu pada kajian etnomatematika wilayah Asia lain adalah pada pola bordir Bedouin yang berasal dari busana tradisional perempuan di daerah Israel bagian selatan yang memiliki pola graf star. Pola ini terdapat di bagian leher hingga dada yang menyerupai bentuk bunga (Fouze \& Amit, 2019).

Konsep geometri bangun datar untuk dijadikan sebagai bahan referensi dalam kurikulum sekolah yang terdapat pada motif Batik Lebak adalah konsep belah ketupat, persegi panjang, segitiga, lingkaran dan graf star. Alternatif penggunaan motif batik Lebak dalam pembelajaran geometri bidang di 
sekolah dapat digunakan pada pengenalan garis, dan pengenalan bangun datar sederhana.

\section{Simpulan}

Motif batik Lebak memuat aspek geometris belah ketupat diantaranya motif batik gula sakojor, motif pare sapocong, motif caruluk saruntuy, motif angklung buhun, dan motif kalimaya. Kedua memuat aspek geometris persegi panjang diantaranya motif pare sapocong, motif sadulur, dan motif Lebak bertauhid. Ketiga memuat aspek geometris lingkaran diantaranya motif caruluk saruntuy, motif kalimaya, motif Lebak bertauhid, motif rangkasbitung. Keempat memuat aspek geometris segitiga diantaranya motif kahirupan baduy, dan motif sadulur. Kelima memuat graf star diantaranya motif caruluk saruntuy dan motif sadulur. Ide-ide matematis geometri yang termuat motif Batik Lebak adalah simetri pada titik, simetri pada garis, persegi panjang, belah ketupat, lingkaran dan graf star.

\section{Daftar Pustaka}

Afriyanty, M., \& Izzati, N. (2019). Eksplorasi Etnomatematika pada Corak Alat Musik Kesenian Marawis Sebagai Sumber Belajar Matematika. Jurnal Gantang 4 (1), 39-48.

Arwanto. (2017). Eksplorasi Etnomatematika Batik Trusmi Cirebon untuk Mengungkap Nilai Filosofi dan Konsep Matematis. Phenomenon 7(1), 40-49.

Choirudin, Ningsih, E. F., Anwar, M. S., Sari, I. R.,\& Amalia, S. (2020). Pengembangan Perangkat Pembelajaran Etnomatematika Pada Situs Purbakala Pugung Raharjo. Pi: Mathematics Education Journal 3(1), 18-27.

Fajriyah, E. (2018). Peran Etnomatematika Terkait Konsep Matematika dalam Mendukung Literasi. Prisma, Prosiding Seminar Nasional Matematika, 114-119.

Firdaus, B. A. B., Widodo, S. A., Taufiq, I.,\& Irfan, M. (2020). Studi Etnomatematika: Aktivitas Petani Padi Dusun Panggang. Jurnal Derivat 7(2), 85-92.

Fouze, A.Q., \& Amit, M. (2019). Ethnomathematics and Geometrical Shapes in Bedouin Women's Traditional Dress. Creative Education 10, 1539-1560.

Gravemeijer, K. (1997). Commentary Solving Word Problems: A Case of Modelling. Learning and Instruction 7(4), 389-397.

Lubis, A. N. M. T., \& Widada, W. (2020). Kemampuan Problem Solving Siswa Melalui Model Pembelajaran Matematika Realistik Berorientasi Etnomatematika Bengkulu. Jurnal Pendidikan Matematika Raflesia 5(1), 127-133.

Maharani, A. \& Maulidia, S. (2018). Etnomatematika Dalam Rumah Adat Penjalin. Wacana Akademika 2(2), 224-235.

Nisa, R. (2020). Eksplorasi Etnomatematika Pada Batik Pamiluto Gresik. Briliant: Jurnal Riset dan Konseptual, 442-448.

Nurjamil, D., \& Nurhayati, E. (2019). Eksplorasi Unsur Matematika dalam Pembuatan Batik Khas Tasikmalaya. Jurnal Matematika Ilmiah STKIP Muhammadiyah Kuningan 5(2), 111119.

Prabawati, M.N. (2016). Etnomatematika Masyarakat Pengrajin Anyaman Rajapolah Kabupaten Tasikmalaya. Jurnal Ilmiah Program Studi Matematika 5(1), 25-31.

Pramudita, K. \& Rosnawati, R. (2019). Exploration Of Javanese Culture Ethnomatematics Based On Geometry Perspective. Journal of Physics: Conference Series 1200(1), 1-8. 
Ridwan, H. (2018). Etnomatematika: Tinjauan Aspek Geometris Tenun Suku Baduy di Desa Kanekes Kabupaten Lebak Provinsi Banten.Tesis. Universitas Pendidikan Indonesia, Bandung.

Sahilda, Y., \& Izzati, N. (2020). Eksplorasi Etnomatematika Motif Batik Gonggong TanjungPinang Kepulauan Riau. AlKhawarizmi: Jurnal Pendidikan dan Pembelajaran Matematika 4(1), 79-92.

Setiawan W., \& Listiana,Y. (2021). Eksplorasi Etnomatematika Pada Batik Mojokerto. Jurnal Pendidikan Matematika 7(1), 62-70.

Sudirman, Son, A.L.,\& Rosyadi. (2018). Penggunaan Etnomatematika Pada Batik Paoman Dalam Pembelajaran Geometri Bidang Di Sekolah Dasar. IndoMath: Indonesia Mathematics Education 1(1), 27-34.

Susanty, P.I., Zaenuri,M., \& Kharisudin, I. (2019). Eksplorasi Etnomatematika Alat Musik Gong Waning Masyarakat Sikka. Prosiding Seminar Nasional Pascasarjana, 255-259.

Zayyadi, M. (2017). Eksplorasi Etnomatematika Pada Batik Madura. Zigma 2(2), 35-40. 